\title{
The Role of Complement in Synaptic Pruning and Neurodegeneration
}

\author{
Angela Gomez-Arboledas (D) \\ Munjal M Acharya $\mathbb{D D}^{2,3}$ \\ Andrea J Tenner $\mathbb{D}^{1,4,5}$ \\ 'Department of Molecular Biology and \\ Biochemistry, University of California, \\ Irvine, Irvine, CA, USA; ${ }^{2}$ Department of \\ Anatomy and Neurobiology, University of \\ California, Irvine, Irvine, CA, USA; \\ ${ }^{3}$ Department of Radiation Oncology, \\ University of California, Irvine, Irvine, \\ CA, USA; ${ }^{4}$ Department of Neurobiology \\ and Behavior, University of California \\ Irvine, Irvine, CA, USA; ${ }^{5}$ Department of \\ Pathology and Laboratory Medicine, \\ University of California, Irvine, School of \\ Medicine, Irvine, CA, USA
}

\begin{abstract}
The complement system, an essential part of the innate immune system, is composed of a group of secreted and membrane proteins that collectively participate in maintaining the function of the healthy and diseased brain. However, an inappropriate activation of the complement system has been related to an inflammatory response in multiple diseases, such as stroke, traumatic brain injury, multiple sclerosis, and Alzheimer's disease, as well as Zika infection and radiotherapy. In addition, C1q and C3 (initial activation components of the complement cascade) have been shown to play a key beneficial role in the refinement of synaptic circuits during developmental stages and adult plasticity. Nevertheless, excessive synaptic pruning in the adult brain can be detrimental and has been associated with synaptic loss in several pathological conditions. In this brief review, we will discuss the role of the complement system in synaptic pruning as well as its contribution to neurodegeneration and cognitive deficits. We also mention potential therapeutic approaches to target the complement system to treat several neuroinflammatory diseases and unintended consequences of radiotherapy.
\end{abstract}

Keywords: microglia, C1q, synapses, phagocytosis, inflammation

\section{Introduction}

The complement system, an ancient and critical component of the immune response, plays an essential role in maintaining brain homeostasis as it participates in host defense by quickly recognizing and eliminating pathogens, cellular debris and misfolded proteins. It is composed of more than 40 proteins that act as a cascade strategy, leading to the generation of various opsonins, anaphylatoxins and ultimately, the membrane attack complex (MAC) (Figure 1). The complement system can be activated by different stimuli through three different recognition pathways (the classical, the alternative and the lectin pathways). All three converge at $\mathrm{C} 3$, which is cleaved into $\mathrm{C} 3 \mathrm{~b} / \mathrm{iC} 3 \mathrm{~b}$, and ultimately can lead to the production of proinflammatory $\mathrm{C} 5 \mathrm{a}$ and formation of the MAC. ${ }^{1,2}$ Regardless of the activation mechanism, the functional results are as follows: 1) opsonization of pathogens and ingestion of dying cells, 2) phagocytic cell chemotaxis to the site of the injury, 3) increased local vascular permeability, and 4) MAC formation creating a pore in the pathogen cell membrane, which results in pathogen lysis. ${ }^{2,3}$ During development, the complement system takes part in the refinement of synaptic circuits in which less active synaptic connections are eliminated. This process, known as synaptic pruning, involves the phagocytosis of "weak" or inactive synapses by microglial cells $^{4}$ via engagement of synapse-bound $\mathrm{iC} 3 \mathrm{~b}$ and the microglial CR3 complement
Correspondence: Andrea J Tenner Department of Molecular Biology and Biochemistry, University of California Irvine, 3205 McGaugh Hall, Irvine, CA, 92697, USA

Tel + I 949-824-3268

Email atenner@uci.edu 


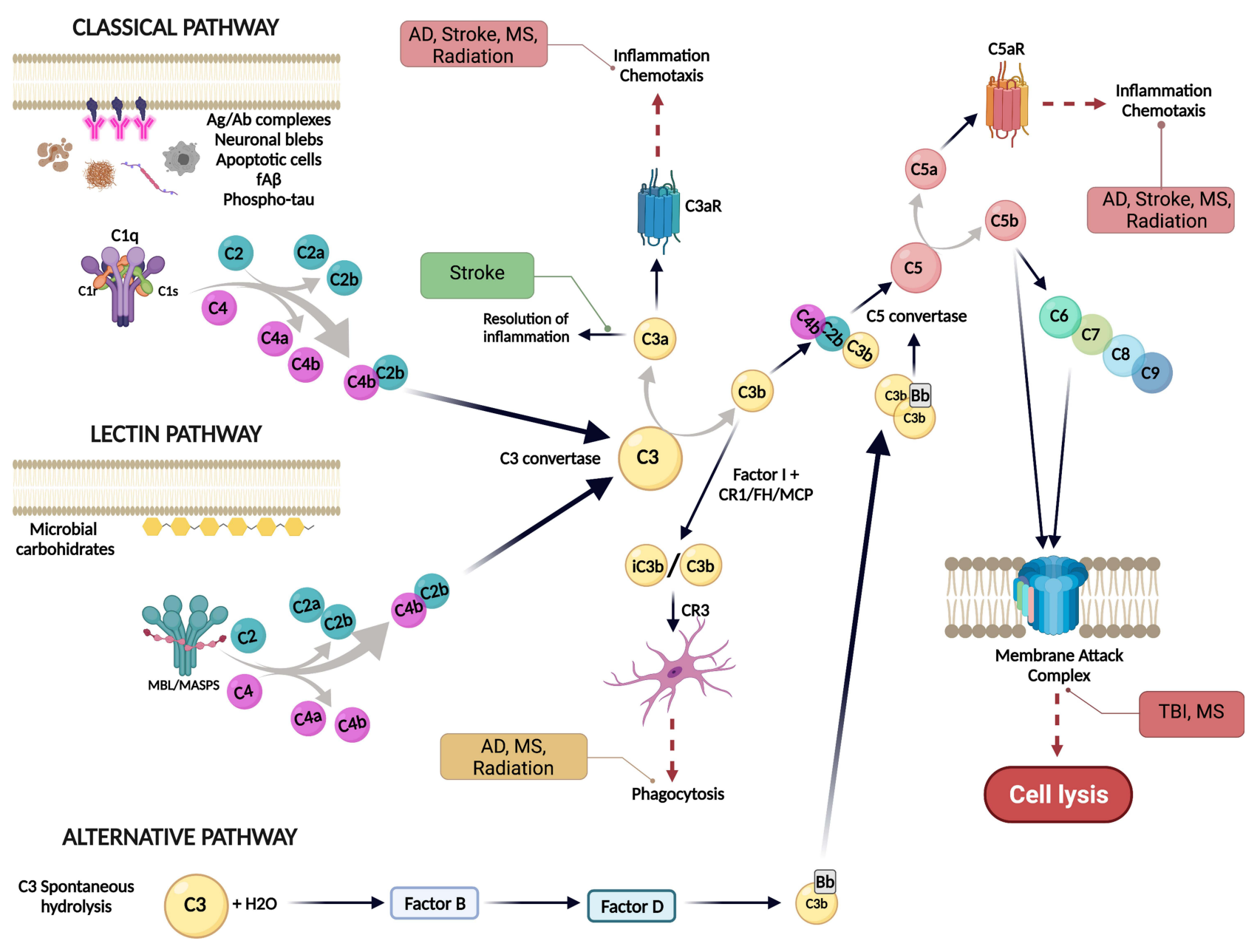

Figure I Overview of the complement system activation pathways. The complement system can be activated by three different pathways: classical, lectin or the alternative pathway. The presence of neuronal blebs, $\mathrm{fA}$, phosphor-tau, apoptotic cells or antigen-antibody complexes can bind to $\mathrm{Cl}$ complex and activate the classical pathway. The lectin pathway is activated when microbial carbohydrates bind mannan-binding lectin (MBL) in complex with MASPI/2 and the alternative pathway is activated by a spontaneous hydrolysis of C3. All three pathways converge at C3, that is cleaved by the C3 convertase into C3a and C3b. C3a promotes chemotaxis via C3aR, while $\mathrm{C} 3 \mathrm{~b}$ could bind to $\mathrm{C} 4 \mathrm{~b} 2 \mathrm{~b}$ to form the $\mathrm{C} 5$ convertase and cleave $\mathrm{C} 5$ into $\mathrm{C} 5 \mathrm{a}$ and $\mathrm{C} 5 \mathrm{~b}$. $\mathrm{C} 5 \mathrm{a}$ is a potent inflammatory effector that promotes chemotaxis and activation through C5aRI, while C5b binds to C6, C7, C8 and C9 to form the membrane attack complex (MAC) to induce cell lysis. Green boxes indicate a beneficial role of the complement system, orange boxes mean that the effect can be either beneficial or detrimental if dysregulated and red boxes denote a detrimental effect of the complement system associated with specific conditions. Created with BioRender.com.

receptor $(\mathrm{CD} 11 \mathrm{~b} / \mathrm{CD} 18) .{ }^{5}$ Besides its multiple beneficial functions in brain homeostasis, the complement system has also been implicated in neurodegeneration. Multiple complement proteins (such as $\mathrm{C} 1 \mathrm{q}, \mathrm{C} 3$ or $\mathrm{C} 4$ ) have been found to be elevated in the brains of patients with Huntington's Disease (HD), Alzheimer's disease (AD) and Parkinson's disease (PD), among others. ${ }^{6}$ Under pathological conditions, such as Alzheimer's disease (AD), virus infection or radiation-induced injury, excessive complement-mediated synaptic pruning results in an excessive elimination of synapses and is associated with cognitive impairment. ${ }^{7-9}$ In addition, the chemotactic complement activation fragments, $\mathrm{C} 3 \mathrm{a}$ and $\mathrm{C} 5 \mathrm{a}$, may synergize with other inflammatory signals, to generate neurotoxic inflammation. In this review, we will explore the beneficial and detrimental roles of the complement system in the brain, followed by a focus on neurodegeneration and its implications for the treatment of brain cancer. Preclinical complement targeted therapeutics are discussed and progress toward potential complement therapies for CNS disorders is addressed.

\section{Complement in the Brain Sources of Complement in the Brain}

Originally, the presence of complement activity was studied as a component of the immune system in blood with a major site of synthesis in the liver. However, 
complement proteins are now recognized to be differentially induced during the development of the nervous system and by injury in multiple cell types in tissues, including CNS resident neurons, astrocytes, oligodendrocytes, and microglia (reviewed in ${ }^{2,10}$ ). Most complement components increase in the brain with aging, and further increase in patients with neurodegenerative diseases and animal models of those diseases. ${ }^{2}$ RNA-seq of sorted brain cell types has provided strong evidence of this in the past few years, ${ }^{11}$ although the source of several components, such as $\mathrm{C} 1 \mathrm{r}, \mathrm{C} 1 \mathrm{~s}$, and $\mathrm{C} 2$, required for the cleavage of first $\mathrm{C} 4$, then, C2 and ultimately C3 (via a C4b2b enzyme complex), and the terminal components remain to be determined as the technology becomes optimized for sensitivity required to detect local synthesis of induced components. In addition, the continuing discovery of molecules in the brain with structures similar to some complement components and complement regulators ${ }^{12-14}$ suggests the need for protection, regulation and repair in the brain and suggest that more novel components may yet to be uncovered.

\section{Synaptic Pruning}

It is well established that during development, excess of synapses (as well as less active synapses) need to be eliminated in order to obtain the appropriate number of synapses and refine the synaptic circuits. This process, most characterized as mediated by microglial cells, is known to involve the classical complement cascade. ${ }^{4}$ In the postnatal CNS and in the retina, $\mathrm{C} 1 \mathrm{q}$ and $\mathrm{C} 3$ were found to be involved in beneficial and necessary synaptic pruning, while in adults, complement-dependent synaptic pruning was shown to be connected to the normal process of forgetting in adults. ${ }^{15}$ It has been proposed that a downregulation of synaptic pruning during development could contribute to cortical hyperconnectivity and behavioral symptoms that characterize individuals with autism, epilepsy, and schizophrenia. ${ }^{16-19}$ The complement component $\mathrm{C} 1 \mathrm{q}$ has been localized at the synapses, ${ }^{4}$ suggesting that $\mathrm{C} 1 \mathrm{q}$ might be tagging weak synapses to be engulfed by microglial cells. Studies with mice lacking C1q, C3, C4 or CR3 showed aberrant synaptic circuits that might be due to an impairment of synaptic pruning. ${ }^{5,16,20,21}$ Further support for the involvement of $\mathrm{C} 1$ comes from recent studies showing a protective effect of the sushi domain protein SRPX2 by binding to $\mathrm{C} 1 \mathrm{q}$ and blocking its function, which thereby protects against excessive complement-mediated synapse elimination. ${ }^{14}$ However, Steven's lab demonstrated that different mechanisms may occur in different brain regions. ${ }^{22}$ Furthermore, while evidence points to microglial engulfment through CR3 receptor, the exact mechanism by which microglial cells phagocytose tagged synapses is still not clear, and several other factors may be required for, or to enhance, this process. Fractalkine (Cx3CL1) and TREM2 signaling in the hippocampus have been related to microglial synaptic pruning. ${ }^{20,23}$ Ding et al recently described the role of $\mathrm{SIRP} \alpha$, a microglial CD47 receptor, in the regulation of synaptic pruning during neurodegeneration. $\operatorname{SIRP} \alpha$ depletion in microglial cells compromises the ability to recognize CD47, a potent "don't eat me" signal, which resulted in the excessive phagocytosis of synapses. ${ }^{24}$ Besides complement-mediated synaptic pruning, Weinhard et al suggested an alternative mechanism, trogocytosis, by which microglial cells might also eliminate synapses in a CR3 independent manner. ${ }^{25}$ The contribution of astrocytes to synaptic pruning has also been described through different mechanism, which involves APOE and Megf10 and MERTK receptors. ${ }^{26,27}$

Despite the beneficial function of synaptic circuit refinement, several groups have described a detrimental effect related to an aberrant complement-mediated synaptic pruning in normal aging as well as in multiple neurodegenerative disorders, such as AD (Figure 2). ${ }^{7,11,28,29}$ When the peak of developmental synaptic pruning has passed, there is a downregulation of $\mathrm{Clq}$ and $\mathrm{C} 3$ in the brain. ${ }^{4,5,30}$ However, accumulation of $\mathrm{C} 1 \mathrm{q}$ at synapses has been shown in mouse models and in post-mortem brain from patients with $\mathrm{AD}$, several tauopathies, and West Nilevirus, and is associated with synaptic loss. ${ }^{8,11,31}$ Moreover, infection by Zika Virus (ZIKV) has been shown to increase the expression of $\mathrm{Clq}$ and $\mathrm{C} 3$ in mice, and an intense microgliosis has been described. Mice infected by ZIKV showed a significant decrease in synaptic number that was directly associated with an increase pruning by microglial cells; suggesting that ZIKV infection leads to activation of the complement system and thus it induces an excessive synaptic pruning, leading to memory impairment in mice. ${ }^{32}$ Deletion or blockage of C1q, C3 or CR3 in mouse models of AD were shown to protect synapses and prevent cognitive impairments. ${ }^{7,11,28}$ Interestingly, synapse depletion and cognitive impairment resulting from Zika virus infection appeared dependent on C3aR rather than CR3. ${ }^{8}$ In addition, it is still unclear what triggers the activation of the complement cascade that leads to excessive synaptic pruning. It has been suggested 

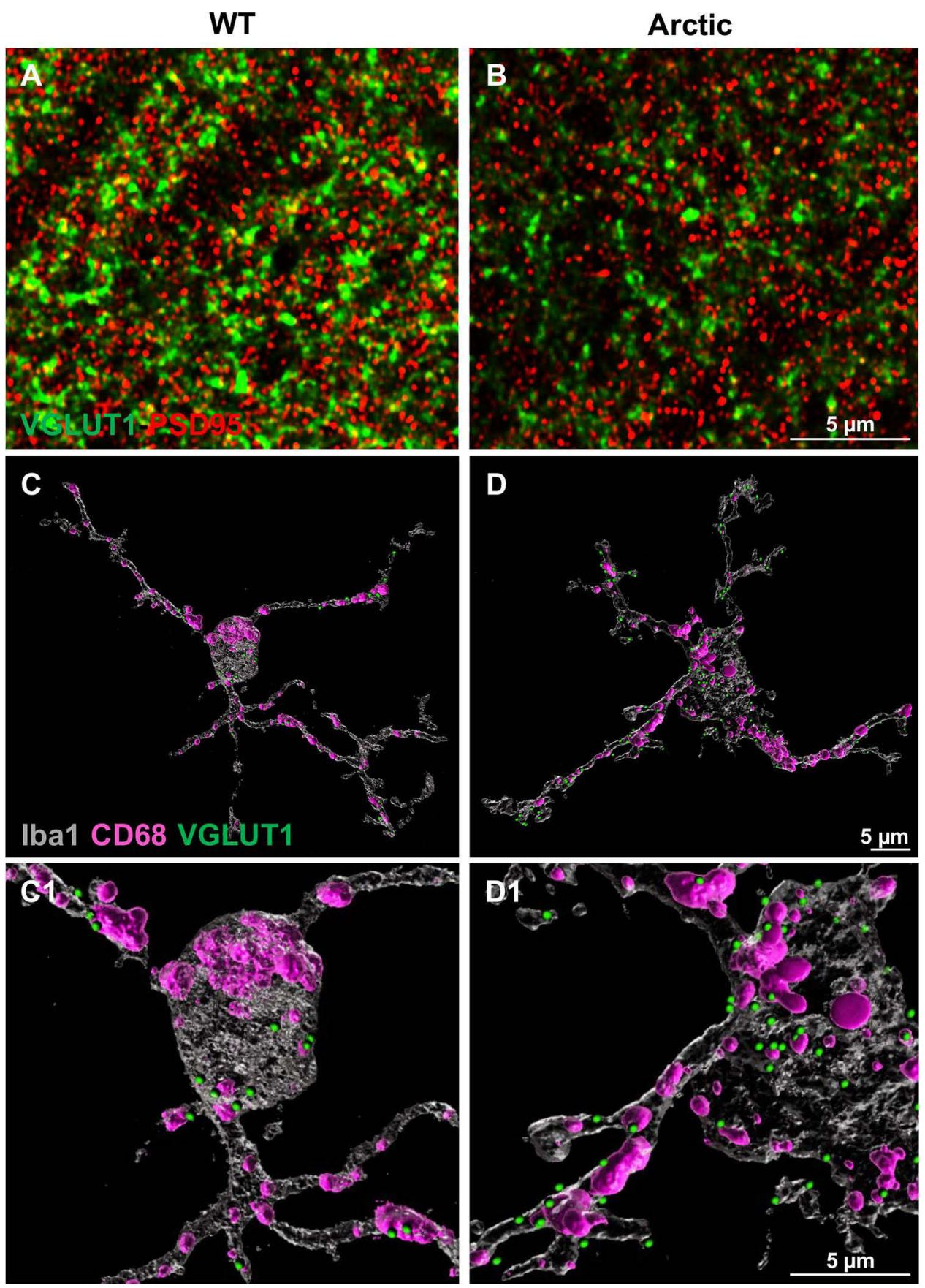

Figure 2 Excessive synaptic loss in a mouse model of Alzheimer's disease. Representative superresolution images of double immunofluorescence for a presynaptic marker (VGLUTI, green) and postsynaptic marker (PSD95, red) in hippocampus from a WT (A) and an Arctic AD model mouse (B) showing the loss of presynapses at I0 months of age. Courtesy of Dr. Maria Fonseca. This synaptic loss could be due to an increase in complement mediated microglial phagocytosis, as shown by a 3D reconstruction of microglia (Ibal, gray), lysosomes (CD68, pink) and presynapses (VGLUTI, green). The Arctic mouse (D-DI) showed an increased VGLUTI within the microglia, when compared to a WT littermate $(\mathbf{C}-\mathbf{C I})$. Scale bars, $5 \mu \mathrm{m}$. All animal procedures were approved by the Institutional Care and Use Committee of University of California Irvine.

that synaptosis (defined as local apoptosis at the individual synapses without neuronal death) could be the leading event. ${ }^{33-35}$ Kardos et al showed an increase in apoptotic markers and evidence of mitochondrial dysfunction in C1q-tagged synaptosomes, which is consistent with shared mechanisms between synaptic pruning and the regular clearance of apoptotic cells by microglia. ${ }^{36,37}$ The aberrant external exposure of phosphatidyl serine or other signals of local damage, a lack of CD47 at the synapse, or "hypoenergetics" that then triggers ingestion have all been suggested. Interestingly, in multiple sclerosis (MS) an excessive synaptic pruning has been associated with 
both an increase in $\mathrm{Clq}^{38,39}$ and a $\mathrm{C} 1 \mathrm{q}$-independent increase in $\mathrm{C} 3$ at the synapses. Moreover, overexpression of Crry (a potent complement inhibitor in mice) at C3bbound synapses, reduced microglial synaptic pruning in a mouse model of demyelinating disease, suggesting a role of the alternative complement pathway in synaptic elimination in MS. ${ }^{40}$ In summary, synaptic pruning is a doubleedge sword that, while contributing to normal synaptic plasticity, when not properly regulated can be detrimental.

\section{Neuroinflammation in the Brain and Therapeutic Potential}

An inflammatory response usually involves multiple mediators and different cells with the ultimate goal of neutralizing the pathogen or injury that initially triggered the process, as well as repairing the damage to the tissue affected by it. Complement-induced cleavage products $\mathrm{C} 3 \mathrm{a}$ and $\mathrm{C} 5 \mathrm{a}$ are known to contribute to inflammation and activation of immune cells expressing $\mathrm{C} 3 \mathrm{aR}$ or C5aR1 (G-protein coupled anaphylatoxin receptors), which leads to the induction of chemotaxis and cell activation including cytokine production. ${ }^{1,41}$ Multiple injuries and/or stimuli can activate the complement system in the $\mathrm{CNS}$, and as a result, the inflammatory response driven by the complement system is present in a wide range of diseases $^{42}$ (Figure 1). While some disorders at least initially involve peripherally derived complement components owing to a compromised blood-brain barrier such as stroke, traumatic brain injury (TBI), and MS, CNS produced complement appears to be the dominant chronic source of these components in many neurodegenerative diseases.

\section{Alzheimer's Disease (AD)}

Alzheimer's disease is the most prevalent cause of dementia around the world and is the sixth leading cause of death in the US. ${ }^{43}$ This devastating neurodegenerative disease is characterized by the presence of amyloid- $\beta$ plaques, neurofibrillary tangles and reactive glial cells. Evidence, including extensive GWAS studies, strongly suggests a key role for inflammation in the progression of the disease (reviewed in $^{44-47}$ ). Several anti-inflammatory therapies have been tested in clinical trials to treat Alzheimer's without success, suggesting that broad inhibition of inflammation is not the key to stop the neuropathology of the disease, but instead, more specific targets are required. ${ }^{44,48}$ The complement system can be activated by fibrillar $\mathrm{A} \beta$ and hyperphosphorylated tau tangles. ${ }^{49-51}$ Moreover, several complement molecules, such as C1q, $\mathrm{C} 3$ or $\mathrm{C} 4$, have been found to co-localize with amyloid plaques in both mouse models of $\mathrm{AD}$ and post-mortem tissue from human AD patients. ${ }^{52-54}$ Studies on different mouse models of $\mathrm{AD}$ have also suggested a role of the complement system in excessive synaptic loss, which also correlates with memory loss and cognitive deficits shown by $\mathrm{AD}$ patients. ${ }^{55}$ As discussed above, accumulation of $\mathrm{C} 1 \mathrm{q}$ and $\mathrm{C} 3$ at the synapses leads to a region-specific excessive synaptic pruning and synapse loss in different mouse models of $\mathrm{AD},{ }^{7,28,56}$ which is attenuated by genetic ablation of $\mathrm{C} 1, \mathrm{C} 3, \mathrm{CR}$ and $\mathrm{CR} 3$. Interestingly, the contribution of $\mathrm{C} 1 \mathrm{q}$ and/or $\mathrm{C} 3$ to the excessive synaptic pruning has been demonstrated at the pre-plaque stage of the disease $^{7}$ as well as in old mice where amyloid plaques were abundant. ${ }^{56}$ In line with this, Fonseca et al showed an improvement in hippocampal synaptophysin and MAP2 at 16 mo in the absence of $\mathrm{C} 1 \mathrm{q}$ in a mouse model of $\mathrm{AD} .^{57}$ However, reports of complement-independent $\mathrm{Clq}$ neuroprotection $^{58,59}$ suggest that upstream inhibition of the complement cascade, at $\mathrm{C} 1 \mathrm{q}$, might not be the right therapeutic target for all stages of $\mathrm{AD}$.

Activation of the complement system can ultimately generate $\mathrm{C} 5 \mathrm{a}$, which binds to its receptor $\mathrm{C} 5 \mathrm{aR} 1$ predominantly detected on microglial cells and contributes to neuroinflammation. In addition, in the Arctic mouse model of $\mathrm{AD}$, genetic ablation of $\mathrm{C} 5 \mathrm{aR} 1$ reduced memory loss, prevented the loss of neuronal complexity in the CA1 region of the hippocampus and polarized microglial cells towards a less inflammatory phenotype.$^{60}$ Moreover, pharmacological inhibition using a C5aR1 antagonist (PMX205) showed a significant reduction of amyloid pathology, glial reactivity and rescued synaptic and cognitive deficits in two different mouse models of AD (Tg2576 and $3 \times \mathrm{XTg}) .{ }^{61}$ Toxicity studies with PMX205 in mice suggest that repeat dosing of PMX205 is well tolerated and no drug accumulation was found in tissue. ${ }^{62}$ More importantly, the extended use of other C5aR1 antagonists, PMX53 and Avacopan, showed no safety issues in human clinical trials for peripheral inflammatory disorders. ${ }^{63,64}$ These results suggest C5a-C5aR1 signaling as a better therapeutic target than the upstream complement components, $\mathrm{C} 1 \mathrm{q}$ and $\mathrm{C} 3$, by suppressing the detrimental effects of a chronic complement activation while maintaining the protective roles of $\mathrm{C} 1 \mathrm{q}$ and $\mathrm{C} 3{ }^{58,59}$ 


\section{Stroke}

Ischemic stroke is produced by an interruption of the blood flow into the brain, which is normally followed by a reperfusion of the injured area due to the restoration of the blood flow. This leads to secondary injury caused by an inflammatory reaction mediated by the complement system. Data from human patients showed a prominent deposition of complement $\mathrm{C} 1 \mathrm{q}$ and $\mathrm{C} 3 \mathrm{~d}$ components in the ischemic brain; moreover, complement activation proteins, C5a and C3a, present in the serum of these patients have been correlated with the severity of the pathology and its symptoms. ${ }^{65-67}$ Importantly, several studies in animals showed an increase in complement components (such as $\mathrm{C1q}, \mathrm{C} 3 \mathrm{a}$ and $\mathrm{C} 5 \mathrm{a}$ ) in the post-stroke brain, as well as an upregulation of $\mathrm{C} 1 \mathrm{q}$ mRNA in microglial cells and $\mathrm{C} 5$ mRNA in neurons ${ }^{68}$ (reviewed in $^{69}$ ). Ultimately, this chronic inflammatory reaction culminates in the exacerbation of tissue damage (which involves apoptotic cell death), neurological symptoms and cognitive deficits. ${ }^{70,71}$ On the other hand, after stroke, generation of $\mathrm{C} 3 \mathrm{a}$ also contributes to the recovery of ischemic tissue by promoting regeneration and the resolution of inflammation. ${ }^{72}$ This double-edge sword translates into a challenging task (or opportunity) for targeting complement mediators as a possible therapeutic strategy for this disorder. ${ }^{73}$ However, as it is clear that deposition of $\mathrm{C} 3 \mathrm{~b}$ and thus the subsequent formation of $\mathrm{C} 3$ and $\mathrm{C} 5$ convertases is a central event in stroke pathology, numerous studies have used $\mathrm{C} 3$ as their main target to treat stroke. ${ }^{71,74-76}$ Chimeric molecules composed of a targeting component (like CR2 or an antibody against injury-induced neoepitopes) and $\mathrm{C} 3$ convertase inhibitors such as Factor $\mathrm{H}(\mathrm{fH})^{74}$ or the mouse Crry $^{76}$ have been developed to specifically inhibit C3 convertase activity at the site of injury. While CR2-Crry inhibits all three complement pathways at the C3 level, CR2-fH acts specifically to inhibit the alternative pathway. Both targeted inhibitors resulted in similar protective effects in the acute phase after stroke, but only CR2-fH was protective 7 days after the stroke. These results are consistent with a major contribution of the alternative complement pathway to the pathology after stroke, as well as with the hypothesis of a post-stroke regenerating effect of the complement system. $^{76}$

\section{Traumatic Brain Injury}

TBI is a complex injury where the brain is damaged as a result of different concussions or injuries that usually involve a quick movement within the skull. Similar to stroke, in TBI there is a first injury followed by a secondary neuroinflammatory injury, mediated in part by the complement system, that ultimately leads to neuronal loss, edema and cognitive symptoms (reviewed $i^{77}$ ). Evidence from animal models as well as human patients with TBI showed an increase in the levels of $\mathrm{C} 1 \mathrm{q}, \mathrm{C} 3 \mathrm{~b}, \mathrm{C} 3 \mathrm{~d}$ and MAC in the brain and in the cerebrospinal fluid $(\mathrm{CSF}){ }^{78,79}$ Moreover, other studies showed significant reduction in several complement regulatory proteins, such as CR1, CD59 or C4BP, in plasma astrocyte-derived exosomes suggesting compromised control of the complement activation in the context of TBI. ${ }^{80}$ Experimental studies in mice lacking $\mathrm{C} 4$ showed a reduction in brain damage and reduced motor impairment after a controlled cortical impact (CCI); furthermore, mice given an inhibitor of the classical and the lectin pathway (C1-INH) had reduced cognitive and motor impairment after $\mathrm{CCI},{ }^{81}$ proving the involvement of the classic and the lectin complement pathways in the damage after TBI. As mentioned previously, C3 is a common component for the different complement pathways and so, it has been a target for the development of therapeutic approaches. An early targeting chimeric composed of CRIg to engage C3b and CD59 to suppress MAC-mediated injury showed efficacy in a preclinical TBI mouse model. ${ }^{82}$ In addition, the use of a $\mathrm{C} 6$ antisense oligonucleotide that inhibit $\mathrm{C} 6$ has been shown to directly block MAC formation, resulting in reduced neuroinflammation and improved neurological performance in a model of TBI. Similarly, treatment with a C5 inhibitor, OmCI (Ornithodoros moubata complement inhibitor) up to 15 minutes after TBI also showed beneficial effects and neurology recovery by blocking the generation of $\mathrm{C} 5 \mathrm{~b}$, thereby inhibiting the MAC formation. ${ }^{83}$ The targeted inhibitors, CR2-Crry and CR2-CD59, have been tested on mouse models of CCI showing inhibition of the MAC and short-term neuroprotection, but they were not able to further prevent the chronic impairments associated with TBI. ${ }^{84,85}$ Inhibition of the alternative complement pathway specifically, using the CR2-fH, showed significant improvement in cognition, pointing to the alternative complement pathway as the primary contributor to secondary TBI-induced injury, ${ }^{84}$ and providing proof of principle that controlling this pathway may be clinically effective. 


\section{Multiple Sclerosis (MS)}

Multiple Sclerosis is a chronic neuroinflammatory disease characterized by the appearance of plaques of demyelination, axonal damage and finally axonal loss. Although MS and other demyelinating diseases have traditionally been ${ }^{86}$ considered autoimmune disorders mediated by T-cells, there has long been evidence suggesting a role of the complement system in this pathology. ${ }^{87}$ The process by which the complement system drives brain damage in MS still needs to be fully elucidated. However, two different mechanisms, the "outside-in" theory and the "inside-out" paradigm, have been proposed. The first one refers to the recognition of several antigens by antibodies, as well as antibody-independent myelin tagging, as the starting point for initiating the immune response, while the second one postulates that damaged myelin could act as a potent trigger for the complement system (reviewed in ${ }^{88}$ ). In animal models and MS patients, complement component deposition around the demyelinating plaques has been described, ${ }^{89-92}$ as well as an increase in C4a levels in plasma $^{93}$ and $\mathrm{C} 3, \mathrm{C} 4 \mathrm{~b}$ and the MAC in the CSF of patients. ${ }^{91,94}$ Nevertheless, the role of complement in MS is very complex as only one out of the four types of white matter lesion (type II) seems to present complement component deposition on it, ${ }^{89}$ suggesting a high heterogeneity of white matter lesions in MS. However, a different study of MS tissue from patients with a long disease duration (versus the early disease stages reported above) showed complement deposition across all types of white matter lesion. ${ }^{95}$ Moreover, an increase in complement activation products has been directly associated with the severity of the pathology (reviewed $\mathrm{in}^{18}$ ). In fact, in the EAE (Experimental autoimmune Encephalomyelitis) mouse model of MS, the use of a MAC inhibitor (C6 antisense oligonucleotides) reduced the expression of several inflammatory genes, further supporting the critical role of the MAC in tissue damage in MS. ${ }^{96}$ However, although a C5specific monoclonal antibody drug, Eculizumab, has been proven to prevent MAC formation and it has been approved for its use in Neuromyelitis Optica patients, there are still no studies showing its efficiency in MS patients. ${ }^{97}$ Whether that is due to limited brain penetrance, or a combination of factors remains to be seen.

Apart from demyelination and axonal damage, recent evidence also points to a role of synaptic loss in MS pathology. Excessive $\mathrm{C} 1 \mathrm{q}$ and $\mathrm{C} 3$ deposition at the synapses could mediate microglial phagocytosis through the CR3 receptor, resulting in an excessive synaptic pruning in MS patients ${ }^{38}$ in a similar manner to what has been widely described for $\mathrm{AD}$ (see below). In fact, very recently Ramaglia et al showed that $\mathrm{C} 1 \mathrm{q}$ deposition at the synapses in the CA2 region of the hippocampus was associated with the excessive synaptic pruning and loss of inhibitory synapses, ultimately leading to electrophysiological and behavioral changes in the MS brain as well as in a cuprizone-induced demyelination model. ${ }^{39}$ Interestingly, the specific involvement of $\mathrm{C} 3$ and not $\mathrm{C} 1 \mathrm{q}$ in the excessive synaptic pruning in MS was confirmed in mouse models by the lack of C1q tagging the synapses, synaptic loss in $\mathrm{Clq}$ deficient animals and prevention of synaptic loss using a targeted C3 inhibitor (Crry). ${ }^{40,98}$

\section{Complement Activation in the Irradiated Brain and Cognitive Impairments}

In line with the well-described, reparative and pathological roles of complement cascade in the neurodegenerative conditions, our recent observations have characterized the neuromodulatory role of complement cascade in the irradiated brain. ${ }^{9}$ Cranial radiation therapy (CRT) is a common clinical treatment for primary metastatic brain cancers in combination with chemotherapy. ${ }^{99}$ Despite its cytotoxic and anti-cancer activity, CRT is particularly problematic for the survivors of low-grade gliomas (LGG, WHO grade II and III) and childhood brain cancers. ${ }^{100,101}$ CRT affects multifaceted cognitive domains including learning, memory, attention, multi-tasking and planning that negatively affects a survivor's quality of life. ${ }^{100-103}$ This is a particularly serious problem for the pediatric brain cancer survivors who may experience reductions in I.Q. by as much as 3 points per year. ${ }^{102-104}$ Exposure to targeted or whole-brain irradiation leads to microglial activation and astrogliosis ${ }^{105-109}$ followed by persistent neuroinflammation that is often linked with long-term cognitive deficits and neurodegeneration that parallels some of the hallmarks of neurodegenerative disorders including AD and Parkinson's disease.

A number of neurodegenerative conditions with deficiencies in cognitive domains (AD, ALS, epilepsy) share two key features with CRT-induced neuropathology: i) gliosis as a histopathological hallmark and ii) the onset of cognitive impairment. ${ }^{110-113}$ We have shown a pathological link between CRT-induced elevation in proinflammatory cytokines (TNF $\alpha$, IL-1 $\beta$, IL-1 $\alpha$, IL-18), persistent gliosis (microglial activation and astrogliosis), and 
cognitive deficits. ${ }^{105-109}$ CRT-induced gliosis and the aberrant complement cascade activation can drive the synaptic loss as seen in the AD brain. ${ }^{4,28}$ In the CNS, microglia and astrocytes are the major source of complement components including $\mathrm{Clq}$ and $\mathrm{C} 3$, respectively. ${ }^{114,115}$ We found astrocytic hypertrophy (thicker and longer stelae and increased GFAP volume) and microglial activation (amoeboid morphology and CD68 expression) long-term post-whole brain irradiation (9 Gy $)^{108}$ that was accompanied by elevated co-labeling with $\mathrm{C} 1 \mathrm{q}$ and $\mathrm{C} 3$. Such pathology-associated elevations in complement cascade proteins were linked to spine degradation, ${ }^{116}$ synaptic loss and cognitive impairments ${ }^{105,107}$ following exposure to CRT.

Radiation-induced neurodegenerative role of complement proteins was demonstrated by the genetic approaches. Juvenile (three weeks old), transgenic $\mathrm{C}^{-/}$ mice exposed to 8 Gy photons (X-rays) did not show CRTinduced learning deficits on the spontaneous exploration platform two to three months later. ${ }^{117}$ During the acute (6 h) and sub-acute (7 days) phases, irradiated $C 3^{-/}$mice showed higher proliferation ( $\mathrm{BrdU}^{+}$cells) in the absence of gliosis in the hippocampus. Overall, C3 deficiency was protective against CRT-induced cognitive decline and gliosis when mice were exposed at a young age. However, other upstream or downstream complement components were not measured in this study at the acute $(6 \mathrm{~h})$ or the chronic (2-4 months) post-CRT phases to link cognitive index with the CNS complement status. A similar study by Hinkle et al showed the protective effects of global complement receptor CR3 knockout against CRT-induced neuronal damage and microglial activation. ${ }^{116}$ Two-monthold, male and female CR3-KO mice (mutated CD11b gene, B6.129S4-Itgam ${ }^{\text {tm1 Myd/J }}$ ) were exposed to $10 \mathrm{~Gy}$ photons ( $\mathrm{y}$-irradiation) and hippocampal neuronal morphology and microglial activation were determined one month later. Increased neuroinflammation (CD68 and CD11b) was evident in the irradiated WT male brains accompanied by reduced number of immature (long) spines in the dentate gyrus. In contrast, irradiated CR3KO mice did not show neuroinflammation or spine loss. Interestingly, WT female mice did not show detrimental radiation effects indicating sex differences were playing a role in the CNS radio-response. Foregoing studies analyzing the impact of complement $\mathrm{C} 3$ signaling were limited to elucidating CNS-specific effects of complement protein or receptor knockout given the global (peripheral and CNS) gene silencing approaches. Microglia-selective
C1qa gene silencing was used to study CNS-specific effects of C1q protein knockdown. ${ }^{114} \mathrm{Clq}$-flox mice carrying the $\mathrm{Cx} 3 \mathrm{cr} 1^{\text {CreERT2 }}\left(\mathrm{Clqa}^{F L / F L}: \mathrm{Cx} 3 \mathrm{crl} 1^{\mathrm{CreERT2}}\right)$ displayed selective knockdown of microglial Clqa gene by eight weeks of age. This strategy did not alter the peripheral $\mathrm{C} 1 \mathrm{q}$ and thereby allows the mechanistic determination of CNS-specific C1q-mediated downstream events in the irradiated brain. Cranial irradiation (9 Gy, y-rays) of C1qdeficient mice did not show the cognitive dysfunction, microglial activation (CD68) or the synaptic loss (synaptophysin and SV2a) one-month post-CRT, ${ }^{108}$ thereby providing the direct evidence that depletion of microgliaderived $\mathrm{Clq}$ protected the brain from the adverse neurodegenerative effects of CRT. Radiation-induced robust brain injury may also induce the generation of downstream complement activation products, including $\mathrm{C} 3 \mathrm{a}$ and $\mathrm{C} 5 \mathrm{a}$ leading to the pro-inflammatory polarization of microglia and astrogliosis. We found elevated $\mathrm{C} 3$ and $\mathrm{C} 5 \mathrm{aR} 1$ in the irradiated brain that coincided with elevated TLR4 (danger response), pro-inflammatory cytokines and microglial activation long-term post-CRT. ${ }^{9}$ These data suggest that dysregulation of complement cascade activation leads to the long-term inflammatory injury in the irradiated brain. In conclusion, CRT triggers aberrant CNS complement activation linked to gliosis that damages the synaptic landscape in the irradiated brain, leading to cognitive dysfunction. While the neuromodulatory roles of classical complement cascade proteins may be leveraged to develop effective medical countermeasures against this long-term, debilitating impact of CRT, this approach needs to be investigated in context of brain cancer, as complement cascade proteins have been shown to play a role in tumor proliferation, invasion and immunosuppression within the tumor microenvironment.

\section{Brain Cancer}

Evidence of a significant involvement of the CNS complement system in glioma (glioblastoma multiforme, GBM) carcinogenesis is emerging. Gene expression and immunohistochemistry studies on patient samples have shown that cancerous cells secrete soluble complement inhibitors, including factor $\mathrm{H}$ and factor $\mathrm{H}$ related protein (FHR5) that protects the cancerous site from complement activation. ${ }^{118,119}$ Subsequently, intratumoral injections of antibodies against $\mathrm{C} 1$ inhibitor extended the survival of animals bearing GBM. ${ }^{119}$ On the other hand, complement C1q can promote tumor progression by facilitating proliferation, adhesion, migration and angiogenesis within the 

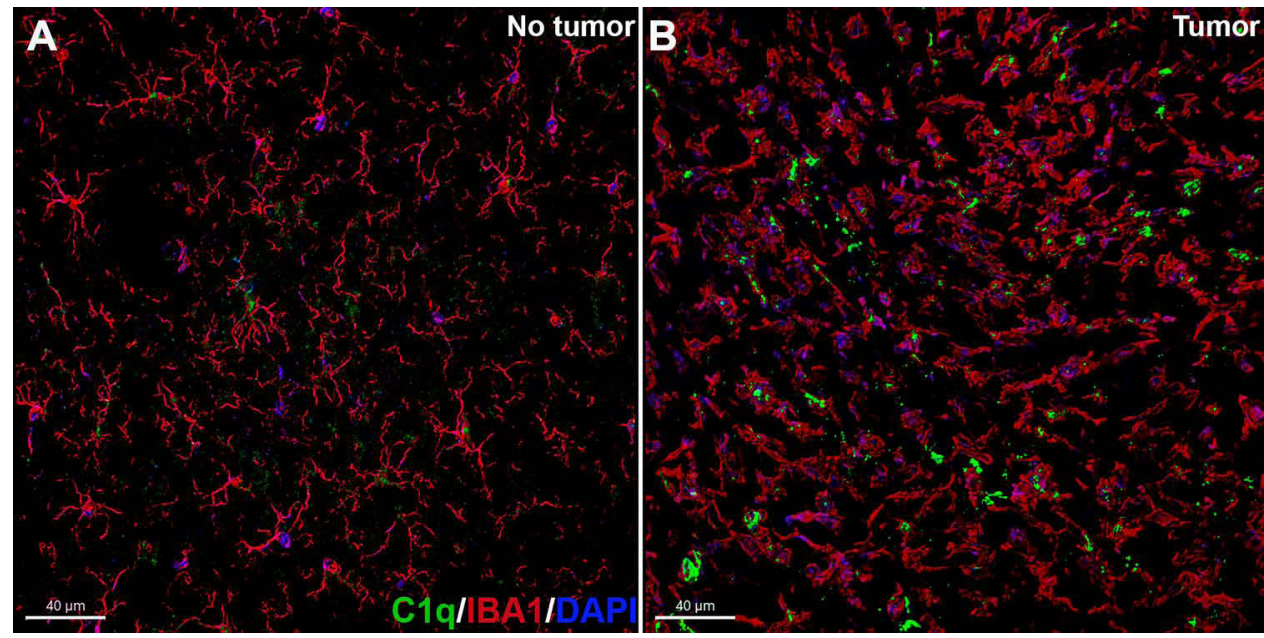

Figure 3 Elevated co-labeling of activated microglia with $\mathrm{Clq}$ in a mouse model of brain cancer. Representative photomicrographs from the confocal $\mathrm{z}$ stacks of double immunofluorescence for microglia (IBAI, red) and $\mathrm{Clq}$ (green) with DAPI (blue or purple) nuclear staining in the contralateral (no cancer, A) and ipsilateral (cancerous, B) to the injection site of CT-2A cells (astrocytoma) in the frontal cortex at 3.5 weeks later. The cancerous site shows activated state of microglia (amoeboid morphology) with higher $\mathrm{Clq}$ expression compared to the non-cancerous site. Scale bar, $40 \mu \mathrm{m}$. All animal procedures were approved by the Institutional Care and Use Committee of University of California Irvine.

tumor microenvironment. Elevated $\mathrm{C} 1 \mathrm{q}$ deposition has been found surrounding the human GBM and malignant neoplasms and necrotic debris. ${ }^{120-122}$ In particular, within the microenvironment of GBM resected from patients, C1q immunoreactivity was co-localized with $\mathrm{CD} 68^{+}$activated microglia and tumor-infiltrating, M2-polarized macrophages that contribute to a tumor-promoting microenvironment. ${ }^{123}$ Elevated expression of this microglial/macrophage lysosomal protein (CD68) within the glioma microenvironment has been linked with reduced survival probability. ${ }^{124}$ We also found elevated co-labeling of $\mathrm{C} 1 \mathrm{q}$ with activated microglia (amoeboid morphology) within the tumor microenvironment (Figure 3). Importantly, the Oncomine database mining for genomewide expression (mRNA) analyses of TCGA (The Cancer Genome Atlas) and the CGGA (The Chinese Glioma Genome Atlas) revealed a significant positive correlation between elevated $\mathrm{Clq}$ and unfavorable prognosis (survival) in diverse grades of glioma indicating a protumorigenic role of C1q. ${ }^{125}$ Patient-derived GBM tissues showed increased deposition of $\mathrm{C} 3$ and $\mathrm{C} 5 \mathrm{~b}-9$ complex. ${ }^{122}$ In an ovarian cancer mouse model, disruption of C3a and C5a signaling via genetic knockout or C5aR1 inhibitor (PMX53) treatment impaired angiogenesis. ${ }^{126}$ Similarly, PMX205 (C5aR1 antagonist) showed anti-cancer activity post-irradiation in colorectal cancer. PMX205 increased the therapeutic efficacy of radiotherapy and reduced normal tissue toxicity in the small intestine. ${ }^{127}$ Taken together, the provocative reports regarding the roles of classical complement proteins in glioma and promising anti-cancer efficacy of complement receptor inhibitors (PMX53, PMX205) suggest strategies targeting glioma complement signaling will serve as a dual-edge sword in eradicating cancer and preventing radiation-induced normal tissue toxicity that compromise cognitive function.

\section{Role of Complement in COVID-19 Pathophysiology and Therapeutics}

The appearance of the COVID-19 pandemic last year, a disease caused by severe acute respiratory syndrome, has emphasized the important role of peripheral inflammation in different neurological diseases. This disease is known to cause several neurological symptoms at the same time that it might increase the risk of developing cognitive decline. ${ }^{128}$ Recent data points to the complement system as an important mediator in COVID-19 disease progression, as it can induce a neurotoxic inflammatory response. ${ }^{129,130}$ In fact, the presence of several complement molecules, including $\mathrm{C} 5 \mathrm{a}$, in the blood of COVID-19 patients was correlated with respiratory failure. ${ }^{131}$ Furthermore, preliminary data on a small number of COVID-19 patients treated with Eculizumab (human monoclonal antibody that inhibits C5), AMY-101 (small-size peptide C3 inhibitor) or BB5.1 (anti-C5 blocking monoclonal antibody) showed beneficial results, as patients presented reduced levels of inflammatory markers. ${ }^{132-134}$ However, additional 
studies and clinical trials with increased numbers of human subjects are needed to further explore the specific role of the complement system in COVID-19 pathogenesis as well as the potential for complement targeted therapeutic treatment.

\section{Summary}

Complement component production in the brain is highly regulated with different components produced by different environmental/danger triggers in different cell types. Complement-mediated synaptic pruning and complement-induced neuroinflammation can be beneficial but if excessive results in loss of function and can cause a self-perpetuating feed-forward loop of neurodegeneration. Both genetic and pharmacological evidence supports the requirement for $\mathrm{C} 1 \mathrm{q}, \mathrm{C} 4$ and C3, CR3 and $\mathrm{C} 5 \mathrm{aR} 1$ in many processes, but involvement of the later components of the cascade provides additional and more selective targets for therapeutic development. ${ }^{42,135}$ There has been an accelerated pace in this pharmacologic space with small molecules and, with improved methods for getting biologics into the brain, enthusiasm for translation to the clinic is high. ${ }^{42,136-138}$ In addition, there are other receptors and functions for $\mathrm{Clq}$ and other complement components proposed in the nervous system ${ }^{139-141}$ and other C1q-like molecules that are important for synapse stability, ${ }^{142,143}$ so there is much more to learn in these systems. A full understanding of these processes will enable more targeted therapeutics in the future for a large number of currently untreatable neurological disorders.

\section{Abbreviations}

AD, Alzheimer's disease; CCI, controlled cortical impact; CNS, central nervous system; CRT, cranial radiation therapy; GBM, glioblastoma multiforme; MAC, membrane attack complex; MS, Multiple Sclerosis; TBI, Traumatic Brain Injury.

\section{Funding}

NIA R01 AG060148 (AJT): and American Cancer Society Research Scholar Grant (RSG-17-146-01-CCE) and NIH award (1R01CA25110) to MMA.

\section{Disclosure}

The authors report no conflicts of interest in this work.

\section{References}

1. Lo MW, Woodruff TM. Complement: bridging the innate and adaptive immune systems in sterile inflammation. J Leukoc Biol. 2020;108(1):339-351. doi:10.1002/JLB.3MIR0220-270R

2. Schartz ND, Tenner AJ. The good, the bad, and the opportunities of the complement system in neurodegenerative disease. J Neuroinflammation. 2020;17(1):354.

3. Tenner AJ. Complement-mediated events in Alzheimer's disease: mechanisms and potential therapeutic targets. J Immunol. 2020;204(2):306-315. doi:10.4049/jimmunol.1901068

4. Stevens B, Allen NJ, Vazquez LE, et al. The classical complement cascade mediates CNS synapse elimination. Cell. 2007;131 (6):1164-1178. doi:10.1016/j.cell.2007.10.036

5. Schafer DP, Lehrman EK, Kautzman AG, et al. Microglia sculpt postnatal neural circuits in an activity and complement-dependent manner. Neuron. 2012;74(4):691-705. doi:10.1016/j.neuron.2012. 03.026

6. Fatoba O, Itokazu T, Yamashita T. Complement cascade functions during brain development and neurodegeneration. FEBS J. 2021. doi: $10.1111 /$ febs. 15772

7. Hong S, Beja-Glasser VF, Nfonoyim BM, et al. Complement and microglia mediate early synapse loss in Alzheimer mouse models. Science. 2016;352(6286):712-716. doi:10.1126/science.aad8373

8. Vasek MJ, Garber C, Dorsey D, et al. A complement-microglial axis drives synapse loss during virus-induced memory impairment. Nature. 2016;534(7608):538-543. doi:10.1038/ nature 18283

9. Markarian M, Krattli RP, Baddour JD, et al. Glia-selective deletion of complement $\mathrm{Clq}$ prevents radiation-induced cognitive deficits and neuroinflammation. Cancer Res. 2020;81(7):17321744. doi:10.1158/0008-5472.CAN-20-2565.

10. Tenner AJ, Stevens B, Woodruff TM. New tricks for an ancient system: physiological and pathological roles of complement in the CNS. Mol Immunol. 2018;102:3-13. doi:10.1016/j.molimm. 2018.06.264

11. Wu T, Dejanovic B, Gandham VD, et al. Complement C3 is activated in human $\mathrm{AD}$ brain and is required for neurodegeneration in mouse models of amyloidosis and tauopathy. Cell Rep. 2019;28(8):2111-2123e2116. doi:10.1016/j.celrep.2019.07.060

12. Zhu H, Meissner LE, Byrnes C, Tuymetova G, Tifft CJ, Proia RL. The complement regulator susd 4 influences nervous-system function and neuronal morphology in mice. iScience. 2020;23 (3):100957. doi:10.1016/j.isci.2020.100957

13. Matsuda K. Synapse organization and modulation via C1q family proteins and their receptors in the central nervous system. Neurosci Res. 2017;116:46-53. doi:10.1016/j.neures.2016.11.004

14. Cong Q, Soteros BM, Wollet M, Kim JH, Sia GM. The endogenous neuronal complement inhibitor SRPX2 protects against complement-mediated synapse elimination during development. Nat Neurosci. 2020;23(9):1067-1078. doi:10.1038/s41593-0200672-0

15. Wang $\mathrm{C}$, Yue $\mathrm{H}, \mathrm{Hu} \mathrm{Z}$, et al. Microglia mediate forgetting via complement-dependent synaptic elimination. Science. 2020;367 (6478):688-694. doi:10.1126/science.aaz2288

16. Sekar A, Bialas AR, de Rivera H, et al. Schizophrenia risk from complex variation of complement component 4. Nature. 2016;530 (7589):177-183. doi:10.1038/nature16549

17. Fagan K, Crider A, Ahmed AO, Pillai A. Complement C3 expression is decreased in autism spectrum disorder subjects and contributes to behavioral deficits in rodents. Mol Neuropsychiatry. 2017;3(1):19-27. doi:10.1159/000465523

18. Ziabska K, Ziemka-Nalecz M, Pawelec P, Sypecka J, Zalewska T. Aberrant complement system activation in neurological disorders. Int J Mol Sci. 2021;22(9):4675. doi:10.3390/ijms22094675 
19. Yilmaz M, Yalcin E, Presumey J, et al. Overexpression of schizophrenia susceptibility factor human complement C4A promotes excessive synaptic loss and behavioral changes in mice. Nat Neurosci. 2020;24(2):214-224. doi:10.1038/s41593-020-00763-8.

20. Paolicelli RC, Bolasco G, Pagani F, et al. Synaptic pruning by microglia is necessary for normal brain development. Science. 2011;333(6048):1456-1458. doi:10.1126/science. 1202529

21. Chu Y, Jin X, Parada I, et al. Enhanced synaptic connectivity and epilepsy in C1q knockout mice. Proc Natl Acad Sci U S A. 2010;107(17):7975-7980. doi:10.1073/pnas.0913449107

22. Welsh Ca, Stephany CE, Sapp RW, Stevens B. Ocular dominance plasticity in binocular primary visual cortex does not require C1q. J Neurosci. 2020;40(4):769-783. doi:10.1523/JNEUROSCI.101119.2019

23. Filipello F, Morini R, Corradini I, et al. The microglial innate immune receptor TREM2 is required for synapse elimination and normal brain connectivity. Immunity. 2018;48(5):979-991e978. doi:10.1016/j.immuni.2018.04.016

24. Ding X, Wang J, Huang M, et al. Loss of microglial SIRPalpha promotes synaptic pruning in preclinical models of neurodegeneration. Nat Commun. 2021;12(1):2030. doi:10.1038/ s41467-021-22301-1

25. Weinhard L, Di Bartolomei G, Bolasco G, et al. Microglia remodel synapses by presynaptic trogocytosis and spine head filopodia induction. Nat Commun. 2018;9(1):1228. doi:10.1038/s41467018-03566-5

26. Chung WS, Clarke LE, Wang GX, et al. Astrocytes mediate synapse elimination through MEGF10 and MERTK pathways. Nature. 2013;504(7480):394-400. doi:10.1038/nature12776

27. Chung WS, Verghese PB, Chakraborty $C$, et al. Novel allele-dependent role for APOE in controlling the rate of synapse pruning by astrocytes. Proc Natl Acad Sci U S A. 2016;113 (36):10186-10191. doi:10.1073/pnas.1609896113

28. Shi Q, Colodner KJ, Matousek SB, et al. Complement C3-deficient mice fail to display age-related hippocampal decline. $J$ Neurosci. 2015;35(38):13029-13042. doi:10.1523/JNEUROSCI.1698-15.2015

29. Vukojicic A, Delestree N, Fletcher EV, et al. The classical complement pathway mediates microglia-dependent remodeling of spinal motor circuits during development and in SMA. Cell Rep. 2019;29 (10):3087-3100e3087. doi:10.1016/j.celrep.2019.11.013

30. Stephan AH, Madison DV, Mateos JM, et al. A dramatic increase of C1q protein in the CNS during normal aging. J Neurosci. 2013;33 (33):13460-13474. doi:10.1523/JNEUROSCI.1333-13.2013

31. Lui H, Zhang J, Makinson SR, et al. Progranulin deficiency promotes circuit-specific synaptic pruning by microglia via complement activation. Cell. 2016;165(4):921-935. doi:10.1016/j. cell.2016.04.001

32. Figueiredo CP, Barros-Aragao FGQ, Neris RLS, et al. Zika virus replicates in adult human brain tissue and impairs synapses and memory in mice. Nat Commun. 2019;10(1):3890. doi:10.1038/ s41467-019-11866-7

33. Mattson MP, Partin J, Begley JG. Amyloid beta-peptide induces apoptosis-related events in synapses and dendrites. Brain Res. 1998;807(1-2):167-176. doi:10.1016/S0006-8993(98)00763-X

34. Park G, Nhan HS, Tyan SH, et al. Caspase activation and caspasemediated cleavage of APP is associated with amyloid beta-protein -induced synapse loss in Alzheimer's disease. Cell Rep. 2020;31 (13):107839. doi:10.1016/j.celrep.2020.107839

35. Erturk A, Wang Y, Sheng M. Local pruning of dendrites and spines by caspase-3-dependent and proteasome-limited mechanisms. J Neurosci. 2014;34(5):1672-1688. doi:10.1523/ JNEUROSCI.3121-13.2014

36. Gyorffy BA, Kun J, Torok G, et al. Local apoptotic-like mechanisms underlie complement-mediated synaptic pruning. Proc Natl Acad Sci U S A. 2018;115(24):6303-6308. doi:10.1073/ pnas. 1722613115
37. Gyorffy BA, Toth V, Torok G, et al. Synaptic mitochondrial dysfunction and septin accumulation are linked to complementmediated synapse loss in an Alzheimer's disease animal model. Cell Mol Life Sci. 2020;77(24):5243-5258. doi:10.1007/s00018020-03468-0

38. Michailidou I, Willems JG, Kooi EJ, et al. Complement C1q-C3associated synaptic changes in multiple sclerosis hippocampus. Ann Neurol. 2015;77(6):1007-1026. doi:10.1002/ana.24398

39. Ramaglia V, Dubey M, Malpede MA, et al. Complementassociated loss of CA2 inhibitory synapses in the demyelinated hippocampus impairs memory. Acta Neuropathol. 2021:1-25. doi:10.1007/s00401-021-02338-8

40. Werneburg S, Jung J, Kunjamma RB, et al. Targeted complement inhibition at synapses prevents microglial synaptic engulfment and synapse loss in demyelinating disease. Immunity. 2020;52 (1):167-182e167. doi:10.1016/j.immuni.2019.12.004

41. Markiewski MM, Lambris JD. The role of complement in inflammatory diseases from behind the scenes into the spotlight. $\mathrm{Am}$ J Pathol. 2007;171(3):715-727. doi:10.2353/ajpath.2007.070166

42. Garred P, Tenner AJ, Mollnes TE. Therapeutic targeting of the complement system: from rare diseases to pandemics. Pharmacol Rev. 2021;73(2):792-827. doi:10.1124/pharmrev.120.000072

43. Alzheimer's Association. Facts and figures; 2020. Available from: https://www.alz.org/alzheimers-dementia/facts-figures. Accessed September 6, 2021.

44. Wyss-Coray $T$, Rogers J. Inflammation in Alzheimer disease-a brief review of the basic science and clinical literature. Cold Spring Harb Perspect Med. 2012;2(1):a006346. doi:10.1101/cshperspect.a006346

45. Carpanini SM, Harwood JC, Baker E, et al. The impact of complement genes on the risk of late-onset Alzheimer's disease. Genes (Basel). 2021;12(3):443. doi:10.3390/genes12030443

46. Kunkle BW, Grenier-Boley B, Sims R, et al. Genetic metaanalysis of diagnosed Alzheimer's disease identifies new risk loci and implicates Abeta, tau, immunity and lipid processing. Nat Genet. 2019;51(3):414-430.

47. Akiyama $\mathrm{H}$, Barger $\mathrm{S}$, Barnum $\mathrm{S}$, et al. Inflammation and Alzheimer's disease. Neurobiol Aging. 2000;21(3):383-421. doi:10.1016/S0197-4580(00)00124-X

48. Rivers-Auty J, Mather AE, Peters R, Lawrence CB, Brough D. Anti-inflammatories in Alzheimer's disease-potential therapy or spurious correlate? Brain Commun. 2020;2(2):fcaa109. doi:10.10 93/braincomms/fcaa109

49. Velazquez P, Cribbs DH, Poulos TL, Tenner AJ. Aspartate residue 7 in amyloid beta-protein is critical for classical complement pathway activation: implications for Alzheimer's disease pathogenesis. Nat Med. 1997;3(1):77-79. doi:10.1038/nm0197-77

50. Shen Y, Lue L, Yang L, et al. Complement activation by neurofibrillary tangles in Alzheimer's disease. Neurosci Lett. 2001;305 (3):165-168. doi:10.1016/S0304-3940(01)01842-0

51. Rogers J, Cooper NR, Webster S, et al. Complement activation by beta-amyloid in Alzheimer disease. ProcNatlAcadSci. 1992;89 (21):10016-10020. doi:10.1073/pnas.89.21.10016

52. Zhou J, Fonseca MI, Pisalyaput K, Tenner AJ. Complement C3 and $\mathrm{C} 4$ expression in $\mathrm{C} 1 \mathrm{q}$ sufficient and deficient mouse models of Alzheimer's disease. J Neurochem. 2008;106(5):2080-2092. doi:10.1111/j.1471-4159.2008.05558.x

53. Fonseca MI, Chu SH, Berci AM, et al. Contribution of complement activation pathways to neuropathology differs among mouse models of Alzheimer's disease. J Neuroinflammation. 2011;8 (1):4. doi:10.1186/1742-2094-8-4

54. Afagh A, Cummings BJ, Cribbs DH, Cotman CW, Tenner AJ. Localization and cell association of C1q in Alzheimer's disease brain. Exp Neurol. 1996;138(1):22-32. doi:10.1006/exnr.1996.0043

55. Selkoe DJ. Alzheimer's disease is a synaptic failure. Science. 2002;298(5594):789-791. doi:10.1126/science.1074069 
56. Shi Q, Chowdhury S, Ma R, et al. Complement C3 deficiency protects against neurodegeneration in aged plaque-rich APP/PS1 mice. Sci Transl Med. 2017;9(392):392. doi:10.1126/scitranslmed.aaf6295

57. Fonseca MI, Zhou J, Botto M, Tenner AJ. Absence of C1q leads to less neuropathology in transgenic mouse models of Alzheimer's disease. J Neurosci. 2004;24(29):6457-6465. doi:10. 1523/JNEUROSCI.0901-04.2004

58. Benoit ME, Hernandez MX, Dinh ML, Benavente F, Vasquez O, Tenner AJ. C1q-induced LRP1B and GPR6 proteins expressed early in Alzheimer's disease mouse models, are essential for the C1q-mediated protection against amyloid-beta neurotoxicity. J Biol Chem. 2013;288(1):654-665.

59. Benoit ME, Clarke EV, Morgado P, Fraser DA, Tenner AJ. Complement protein $\mathrm{C} 1 \mathrm{q}$ directs macrophage polarization and limits inflammasome activity during the uptake of apoptotic cells. J Immunol. 2012;188(11):5682-5693. doi:10.4049/ jimmunol.1103760

60. Hernandez MX, Jiang S, Cole TA, et al. Prevention of C5aR1 signaling delays microglial inflammatory polarization, favors clearance pathways and suppresses cognitive loss. Mol Neurodegener. 2017;12(1):66. doi:10.1186/s13024-017-0210-z

61. Fonseca MI, Ager RR, Chu SH, et al. Treatment with a C5aR antagonist decreases pathology and enhances behavioral performance in murine models of Alzheimer's disease. J Immunol. 2009;183(2):1375-1383. doi:10.4049/jimmunol.0901005

62. Kumar V, Lee JD, Clark RJ, Noakes PG, Taylor SM, Woodruff TM. Preclinical pharmacokinetics of complement C5a receptor antagonists PMX53 and PMX205 in mice. ACS Omega. 2020;5(5):2345-2354. doi:10.1021/acsomega.9b03735

63. Merkel PA, Niles J, Jimenez R, et al. Adjunctive treatment with avacopan, an oral C5a receptor inhibitor, in patients with antineutrophil cytoplasmic antibody-associated vasculitis. ACR Open Rheumatol. 2020;2(11):662-671. doi:10.1002/acr2.11185

64. Vergunst CE, Gerlag DM, Dinant H, et al. Blocking the receptor for C5a in patients with rheumatoid arthritis does not reduce synovial inflammation. Rheumatology(Oxford). 2007;46 (12):1773-1778. doi:10.1093/rheumatology/kem222

65. Pedersen ED, Waje-Andreassen U, Vedeler CA, Aamodt G, Mollnes TE. Systemic complement activation following human acute ischaemic stroke. Clin Exp Immunol. 2004;137(1):117-122. doi:10.1111/j.1365-2249.2004.02489.x

66. Pedersen ED, Loberg EM, Vege E, Daha MR, Maehlen J, Mollnes TE. In situ deposition of complement in human acute brain ischaemia. Scand J Immunol. 2009;69(6):555-562. doi:10. 1111/j.1365-3083.2009.02253.x

67. Szeplaki G, Szegedi R, Hirschberg K, et al. Strong complement activation after acute ischemic stroke is associated with unfavorable outcomes. Atherosclerosis. 2009;204(1):315-320. doi:10. 1016/j.atherosclerosis.2008.07.044

68. Pavlovski D, Thundyil J, Monk PN, Wetsel RA, Taylor SM, Woodruff TM. Generation of complement component C5a by ischemic neurons promotes neuronal apoptosis. FASEB $J$. 2012;26(9):3680-3690. doi:10.1096/fj.11-202382

69. Alawieh A, Elvington A, Tomlinson S. Complement in the homeostatic and ischemic brain. Front Immunol. 2015;6:417. doi:10.3389/fimmu.2015.00417

70. Alawieh A, Langley EF, Tomlinson S. Targeted complement inhibition salvages stressed neurons and inhibits neuroinflammation after stroke in mice. Sci Transl Med. 2018;10(441). Available from: https://link.springer.com/article/10.1007/s00401-02102338-8.

71. Alawieh A, Tomlinson S. Injury site-specific targeting of complement inhibitors for treating stroke. Immunol Rev. 2016;274 (1):270-280. doi:10.1111/imr.12470
72. Ahmad S, Bhatia K, Kindelin A, Ducruet AF. The role of complement C3a receptor in stroke. Neuromolecular Med. 2019;21 (4):467-473. doi:10.1007/s12017-019-08545-7

73. Brennan FH, Anderson AJ, Taylor SM, Woodruff TM, Ruitenberg MJ. Complement activation in the injured central nervous system: another dual-edged sword? J Neuroinflammation. 2012;9(1):137. doi:10.1186/ 1742-2094-9-137

74. Huang Y, Qiao F, Atkinson C, Holers VM, Tomlinson S. A novel targeted inhibitor of the alternative pathway of complement and its therapeutic application in ischemia/reperfusion injury. $J$ Immunol. 2008;181(11):8068-8076. doi:10.4049/jimmunol.181.11.8068

75. Atkinson C, Song H, Lu B, et al. Targeted complement inhibition by C3d recognition ameliorates tissue injury without apparent increase in susceptibility to infection. JClinInvest. 2005;115(9):2444-2453.

76. Alawieh A, Elvington A, Zhu H, et al. Modulation of post-stroke degenerative and regenerative processes and subacute protection by site-targeted inhibition of the alternative pathway of complement. J Neuroinflammation. 2015;12(1):247. doi:10.1186/ s12974-015-0464-8

77. Hammad A, Westacott L, Zaben M. The role of the complement system in traumatic brain injury: a review. $J$ Neuroinflammation. 2018;15(1):24. doi:10.1186/s12974-018-1066-z

78. Bellander BM, Singhrao SK, Ohlsson M, Mattsson P, Svensson M. Complement activation in the human brain after traumatic head injury. J Neurotrauma. 2001;18(12):1295-1311. doi:10.1089/08977150152725605

79. Bellander BM, von Holst H, Fredman P, Svensson M. Activation of the complement cascade and increase of clusterin in the brain following a cortical contusion in the adult rat. $J$ Neurosurg. 1996;85(3):468-475. doi:10.3171/jns.1996.85.3.0468

80. Goetzl EJ, Yaffe K, Peltz CB, et al. Traumatic brain injury increases plasma astrocyte-derived exosome levels of neurotoxic complement proteins. FASEB J. 2020;34(2):3359-3366. doi:10. 1096/fj.201902842R

81. Longhi L, Perego C, Ortolano F, et al. C1-inhibitor attenuates neurobehavioral deficits and reduces contusion volume after controlled cortical impact brain injury in mice. Crit Care Med. 2009;37(2):659-665. doi:10.1097/CCM.0b013e318195998a

82. Ruseva MM, Ramaglia V, Morgan BP, Harris CL. An anticomplement agent that homes to the damaged brain and promotes recovery after traumatic brain injury in mice. Proc Natl Acad Sci U S A. 2015;112 (46):14319-14324. doi:10.1073/pnas.1513698112

83. Fluiter K, Opperhuizen AL, Morgan BP, Baas F, Ramaglia V. Inhibition of the membrane attack complex of the complement system reduces secondary neuroaxonal loss and promotes neurologic recovery after traumatic brain injury in mice. $J$ Immunol. 2014;192(5):2339-2348. doi:10.4049/jimmunol.1302793

84. Alawieh A, Langley EF, Weber S, Adkins D, Tomlinson S. Identifying the role of complement in triggering neuroinflammation after traumatic brain injury. $J$ Neurosci. 2018;38(10): 2519-2532. doi:10.1523/JNEUROSCI.2197-17.2018

85. Alawieh A, Narang A, Tomlinson S. Complementing regeneration. Oncotarget. 2015;6(26):21769-21770. doi:10.186 32/oncotarget.4844

86. Sanders VJ, Felisan S, Waddell A, Tourtellotte WW. Detection of herpesviridae in postmortem multiple sclerosis brain tissue and controls by polymerase chain reaction. J Neurovirol. 1996;2 (4):249-258. doi:10.3109/13550289609146888

87. Lassmann H, Bruck W, Lucchinetti CF. The immunopathology of multiple sclerosis: an overview. Brain Pathol. 2007;17 (2):210-218. doi:10.1111/j.1750-3639.2007.00064.x

88. Morgan BP, Gommerman JL, Ramaglia V. An "outside-in" and "inside-out" consideration of complement in the multiple sclerosis brain: lessons from development and neurodegenerative diseases. Front Cell Neurosci. 2020;14:600656. doi:10.3389/fncel. 2020.600656 
89. Lucchinetti C, Bruck W, Parisi J, Scheithauer B, Rodriguez M, Lassmann H. Heterogeneity of multiple sclerosis lesions: implications for the pathogenesis of demyelination. Ann Neurol. 2000;47(6):707-717. doi:10.1002/1531-8249(200006)47:6<707: AID-ANA3 $>3.0$. CO;2-Q

90. Watkins LM, Neal JW, Loveless S, et al. Complement is activated in progressive multiple sclerosis cortical grey matter lesions. J Neuroinflammation. 2016;13(1):161. doi:10.1186/s12974-0160611-x

91. Aeinehband S, Lindblom RP, Al Nimer F, et al. Complement component $\mathrm{C} 3$ and butyrylcholinesterase activity are associated with neurodegeneration and clinical disability in multiple sclerosis. PLoS One. 2015;10(4):e0122048. doi:10.1371/journal. pone. 0122048

92. Ingram G, Loveless $\mathrm{S}$, Howell OW, et al. Complement activation in multiple sclerosis plaques: an immunohistochemical analysis. Acta Neuropathol Commun. 2014;2(1):53. doi:10.1186/20515960-2-53

93. Ingram G, Hakobyan S, Robertson NP, Morgan BP. Elevated plasma $\mathrm{C} 4 \mathrm{a}$ levels in multiple sclerosis correlate with disease activity. J Neuroimmunol. 2010;223(1-2):124-127. doi:10.1016/ j.jneuroim.2010.03.014

94. Ingram G, Hakobyan S, Hirst CL, et al. Systemic complement profiling in multiple sclerosis as a biomarker of disease state. Mult Scler. 2012;18(10):1401-1411. doi:10.1177/1352458512438238

95. Breij EC, Brink BP, Veerhuis R, et al. Homogeneity of active demyelinating lesions in established multiple sclerosis. Ann Neurol. 2008;63(1):16-25. doi:10.1002/ana.21311

96. Michailidou I, Jongejan A, Vreijling JP, et al. Systemic inhibition of the membrane attack complex impedes neuroinflammation in chronic relapsing experimental autoimmune encephalomyelitis. Acta Neuropathol Commun. 2018;6(1):36. doi:10.1186/s40478018-0536-y

97. Pittock SJ, Berthele A, Fujihara K, et al. Eculizumab in aquaporin-4-positive neuromyelitis optica spectrum disorder. $N$ Engl J Med. 2019;381(7):614-625. doi:10.1056/NEJMoa19 00866

98. Hammond JW, Bellizzi MJ, Ware C, et al. Complementdependent synapse loss and microgliosis in a mouse model of multiple sclerosis. Brain Behav Immun. 2020;87:739-750. doi:10.1016/j.bbi.2020.03.004

99. Stupp R, Mayer M, Kann R, et al. Neoadjuvant chemotherapy and radiotherapy followed by surgery in selected patients with stage IIIB non-small-cell lung cancer: a multicentre Phase II trial. Lancet Oncol. 2009;10(8):785-793. doi:10.1016/S1470-2045(09)70172-X

100. Dietrich J, Gondi V, Mehta M. Delayed complications of cranial irradiation; 2020. Available from: https://www.uptodate.com/ contents/delayed-complications-of-cranial-irradiation. Accessed September 6, 2021.

101. Lawrie TA, Gillespie D, Dowswell T, et al. Long-term neurocognitive and other side effects of radiotherapy, with or without chemotherapy, for glioma. Cochrane Database Syst Rev. 2019;8: CD013047.

102. Merchant TE, Kiehna EN, Kun LE, et al. Phase II trial of conformal radiation therapy for pediatric patients with craniopharyngioma and correlation of surgical factors and radiation dosimetry with change in cognitive function. J Neurosurg. 2006;104(2 Suppl):94-102.

103. Silber JH, Radcliffe J, Peckham V, et al. Whole-brain irradiation and decline in intelligence: the influence of dose and age on IQ score. J Clin Oncol. 1992;10(9):1390-1396. doi:10.1200/ JCO.1992.10.9.1390
104. Merchant TE, Kiehna EN, Li C, et al. Modeling radiation dosimetry to predict cognitive outcomes in pediatric patients with CNS embryonal tumors including medulloblastoma. Int J Radiat Oncol Biol Phys. 2006;65(1):210-221. doi:10.1016/j.ijrobp.2005.10.038

105. Acharya MM, Green KN, Allen BD, et al. Elimination of microglia improves cognitive function following cranial irradiation. Sci Rep. 2016;6(1):31545. doi:10.1038/srep31545

106. Parihar VK, Acharya MM, Roa DE, Bosch O, Christie LA, Limoli CL. Defining functional changes in the brain caused by trageted stereotaxic radiosurgery. Transl Cancer Res. 2014;3(2):124-137.

107. Acharya MM, Baulch JE, Lusardi TA, et al. Adenosine kinase inhibition protects against cranial radiation-induced cognitive dysfunction. Front Mol Neurosci. 2016;9:42. doi:10.3389/fnmol.2016.00042

108. Markarian M, Krattli RP, Alikhani L, et al. Glia-selective deletion of complement $\mathrm{Clq}$ prevents cranial radiation-induce cognitive impairments and neuroinflammation. Cancer Res. 2021;81 (7):1732-1744. doi:10.1158/0008-5472.CAN-20-2565

109. Montay-Gruel P, Acharya MM, Petersson K, et al. Long-term neurocognitive benefits of FLASH radiotherapy driven by reduced reactive oxygen species. Proc Natl Acad Sci U S A. 2019;116(22):10943-10951. doi:10.1073/pnas.1901777116

110. Bell B, Lin JJ, Seidenberg M, Hermann B. The neurobiology of cognitive disorders in temporal lobe epilepsy. Nat Rev Neurol. 2011;7(3):154-164. doi:10.1038/nrneurol.2011.3

111. Palop JJ, Mucke L. Epilepsy and cognitive impairments in Alzheimer's disease. Arch Neurol. 2009;66(4):435-440. doi:10.1001/archneurol.2009.15

112. Rusina R, Ridzon P, Kulist'ak P, et al. Relationship between ALS and the degree of cognitive impairment, markers of neurodegeneration and predictors for poor outcome. A Prospective Study. Eur J Neurol. 2010;17(1):23-30. doi:10.1111/j.1468-1331.2009.02717.x

113. Aarsland D, Kurz MW. The epidemiology of dementia associated with Parkinson's disease. J Neurol Sci. 2010;289(1-2):18-22. doi:10.1016/j.jns.2009.08.034

114. Fonseca MI, Chu SH, Hernandez MX, et al. Cell-specific deletion of C1qa identifies microglia as the dominant source of $\mathrm{C} 1 \mathrm{q}$ in mouse brain. J Neuroinflammation. 2017;14(1):48. doi:10.1186/ s12974-017-0814-9

115. Guttenplan KA, Weigel MK, Adler DI, et al. Knockout of reactive astrocyte activating factors slows disease progression in an ALS mouse model. Nat Commun. 2020;11(1):3753. doi:10.1038/s41467020-17514-9

116. Hinkle JJ, Olschowka JA, Love TM, Williams JP, O’Banion MK. Cranial irradiation mediated spine loss is sex-specific and complement receptor-3 dependent in male mice. Sci Rep. 2019;9 (1):18899. doi:10.1038/s41598-019-55366-6

117. Kalm M, Andreasson U, Bjork-Eriksson T, et al. C3 deficiency ameliorates the negative effects of irradiation of the young brain on hippocampal development and learning. Oncotarget. 2016;7 (15):19382-19394. doi:10.18632/oncotarget.8400

118. DeCordova S, Abdelgany A, Murugaiah V, et al. Secretion of functionally active complement factor $\mathrm{H}$ related protein 5 (FHR5) by primary tumour cells derived from Glioblastoma Multiforme patients. Immunobiology. 2019;224(5):625-631. doi:10.1016/j. imbio.2019.07.006

119. Fornvik K, Ahlstedt J, Osther K, Salford LG, Redebrandt HN. Anti-C1-inactivator treatment of glioblastoma. Oncotarget. 2018;9(100):37421-37428. doi:10.18632/oncotarget.26456

120. Bulla R, Tripodo C, Rami D, et al. C1q acts in the tumour microenvironment as a cancer-promoting factor independently of complement activation. Nat Commun. 2016;7(1):10346. doi: $10.1038 /$ ncomms 10346 
121. Mangogna A, Agostinis C, Bonazza D, et al. Is the complement protein $\mathrm{C} 1 \mathrm{q}$ a pro- or anti-tumorigenic factor? Bioinformatics analysis involving human carcinomas. Front Immunol. 2019;10:865. doi:10.3389/fimmu.2019.00865

122. Bouwens TA, Trouw LA, Veerhuis R, Dirven CM, Lamfers ML, AlKhawaja H. Complement activation in Glioblastoma multiforme pathophysiology: evidence from serum levels and presence of complement activation products in tumor tissue. $J$ Neuroimmunol. 2015;278:271-276. doi:10.1016/j.jneuroim.2014.11.016

123. Galdiero MR, Garlanda C, Jaillon S, Marone G, Mantovani A. Tumor associated macrophages and neutrophils in tumor progression. $J$ Cell Physiol. 2013;228(7):1404-1412. doi:10.1002/jcp.24260

124. Wang L, Zhang C, Zhang Z, et al. Specific clinical and immune features of CD68 in glioma via 1024 samples. Cancer Manag Res. 2018;10:6409-6419. doi:10.2147/CMAR.S183293

125. Mangogna A, Belmonte B, Agostinis C, et al. Prognostic implications of the complement protein $\mathrm{C} 1 \mathrm{q}$ in gliomas. Front Immunol. 2019;10:2366. doi:10.3389/fimmu.2019.02366

126. Nunez-Cruz S, Gimotty PA, Guerra MW, et al. Genetic and pharmacologic inhibition of complement impairs endothelial cell function and ablates ovarian cancer neovascularization. Neoplasia. 2012;14(11):994-1004. doi:10.1593/neo.121262

127. Olcina MM, Melemenidis S, Nambiar DK, et al. Targeting C5aR1 increases the therapeutic window of radiotherapy. bioRxiv. 2020;2020. Available from: https:/www.biorxiv.org/content/10. 1101/2020.10.27.358036v2.full\#: :text=Here\%20we\%20show\% 20 that $\% 20$ targeting,thereby $\% 20$ increasing $\% 20$ the $\% 20$ therapeutic $\% 20$ window.

128. de Erausquin GA, Snyder H, Carrillo M, et al. The chronic neuropsychiatric sequelae of COVID-19: the need for a prospective study of viral impact on brain functioning. Alzheimers Dement. 2021;17 (6):1056-1065. doi:10.1002/alz.12255

129. Yang AC, Kern F, Losada PM, et al. Dysregulation of brain and choroid plexus cell types in severe COVID-19. Nature. 2021;595 (7868):565-571. doi:10.1038/s41586-021-03710-0

130. Boldrini M, Canoll PD, Klein RS. How COVID-19 affects the brain. JAMA Psychiatry. 2021;78(6):682-683. doi:10.1001/ jamapsychiatry.2021.0500

131. Holter JC, Pischke SE, de Boer E, et al. Systemic complement activation is associated with respiratory failure in COVID-19 hospitalized patients. Proc Natl Acad Sci U S A. 2020;117 (40):25018-25025. doi:10.1073/pnas.2010540117

132. Zelek WM, Menzies GE, Brancale A, Stockinger B, Morgan BP. Characterizing the original anti-C5 function-blocking antibody, BB5.1, for species specificity, mode of action and interactions with C5. Immunology. 2020;161(2):103-113. doi:10.1111/imm.13228
133. Mastaglio S, Ruggeri A, Risitano AM, et al. The first case of COVID-19 treated with the complement C3 inhibitor AMY-101. Clin Immunol. 2020;215:108450. doi:10.1016/j.clim.2020.108450

134. Diurno F, Numis FG, Porta G, et al. Eculizumab treatment in patients with COVID-19: preliminary results from real life ASL napoli 2 nord experience. Eur Rev Med Pharmacol Sci. 2020;24 (7):4040-4047.

135. Gavriilaki M, Kimiskidis VK, Gavriilaki E. Precision medicine in neurology: the inspirational paradigm of complement therapeutics. Pharmaceuticals. 2020;13(11):341. doi:10.3390/ ph13110341

136. Zelek WM, Xie L, Morgan BP, Harris CL. Compendium of current complement therapeutics. Mol Immunol. 2019;11 4:341-352. doi:10.1016/j.molimm.2019.07.030

137. Wouters Y, Jaspers T, De Strooper B, Dewilde M. Identification and in vivo characterization of a brain-penetrating nanobody. Fluids Barriers CNS. 2020;17(1):62. doi:10.1186/s12987-02000226-Z

138. Mastellos DC, Ricklin D, Lambris JD. Clinical promise of next-generation complement therapeutics. Nat Rev Drug Discov. 2019;18(9):707-729. doi:10.1038/s41573-019-0031-6

139. Peterson SL, Anderson AJ. Complement and spinal cord injury: traditional and non-traditional aspects of complement cascade function in the injured spinal cord microenvironment. Exp Neurol. 2014;258:35-47. doi:10.1016/j.expneurol.2014.04.028

140. Peterson SL, Nguyen HX, Mendez OA, Anderson AJ. Complement protein $\mathrm{C} 1 \mathrm{q}$ modulates neurite outgrowth in vitro and spinal cord axon regeneration in vivo. $J$ Neurosci. 2015;35 (10):4332-4349. doi:10.1523/JNEUROSCI.4473-12.2015

141. Benavente F, Piltti KM, Hooshmand MJ, et al. Novel C1q receptor-mediated signaling controls neural stem cell behavior and neurorepair. Elife. 2020;9:e55732. doi:10.7554/eLife.55732

142. Yuzaki M. The C1q complement family of synaptic organizers: not just complementary. Curr Opin Neurobiol. 2017;45:9-15. doi:10.1016/j.conb.2017.02.002

143. Suzuki K, Elegheert J, Song I, et al. A synthetic synaptic organizer protein restores glutamatergic neuronal circuits. Science. 2020;369:6507. doi:10.1126/science.abb4853
ImmunoTargets and Therapy

\section{Publish your work in this journal}

ImmunoTargets and Therapy is an international, peer-reviewed open access journal focusing on the immunological basis of diseases, potential targets for immune based therapy and treatment protocols employed to improve patient management. Basic immunology and physiology of the immune system in health, and disease will be also covered. In addition, the journal will focus on the impact of management

\section{Dovepress}

programs and new therapeutic agents and protocols on patient perspectives such as quality of life, adherence and satisfaction. The manuscript management system is completely online and includes a very quick and fair peer-review system, which is all easy to use. Visit http://www.dovepress.com/testimonials.php to read real quotes from published authors. 